\author{
Lukasz Skotnicki \\ Dr inż. \\ Politechnika Wrocławska \\ Wydział Budownictwa Lądowego i Wodnego \\ Katedra Dróg, Mostów, Kolei i Lotnisk \\ lukasz.skotnicki@pwr.edu.pl
}

DOI: 10.35117/A_ENG_21_03_02

\title{
Application of rubber dust in modified asphalts for SMA mixtures
}

\begin{abstract}
The experimental investigation described in the paper refers to the properties of asphalts and asphalt mixtures with addition of rubber wastes. The influence of rubber additive, on rheological properties, viscosity, penetration, softening point of the asphalts were analyzed. An innovative technique based on the combined use of microscopic observations was developed. Tests results were compared to the conventional asphalts. Positive effects of modification were recorded. Two types of asphalt mixtures were prepared on the same mineral aggregate. For reference a Stone Matrix Asphalt (SMA) was used with polymer modified (PM) asphalt 45/80-55. Then the Stone Matrix Asphalt was prepared on the base of asphalt-rubber (45/80-55 AR). These materials were tested on rutting and water and frost resistant. The results indicated that the SMA mixtures prepared on the base of rubber modified asphalt exhibit greater resistance to permanent deformation, at elevated temperatures and greater water and frost resistance than the conventional SMA mixtures. Tests results were compared to technical requirements for SMA layers. It was found that this type of asphalt mixture can be successfully used in road surfaces, especially exposed to freezing.
\end{abstract}

Keywords: Asphalt mixture; SMA mixture; rubber asphalt; Recycling; Dynamic viscosity.

\section{Introduction}

The continuous increase in car traffic forces the use of road surfaces, made of high-resistance materials, to adverse loads. One of the ways to improve the properties of MMA is the use of modified bituminous binders. In connection with the end of a life span of car tires, the question arises what to do with such exploited materials. The issue of the re-use of waste materials (recycling) is a topic increasingly common in construction technology $[1,2,8,13$, $14,23]$. This is also the case with rubber materials $[5,6,11]$. The reuse of waste materials significantly contributes to reducing the consumption of natural resources. In addition, the use of rubber waste leads to a practical solution to the environmental problem: it reduces the negative impact on the environment and reduces the emission of harmful greenhouse gases. The economic benefits obtained in this way cannot be overestimated.

The asphalt-rubber binders are increasingly used for the construction of road and airport pavements. Rubber modified asphalt technology originates from the USA. In 1940, Rubber Reclaiming Company launched a product called Ramflex, which was a dry additive of processed rubber used for road asphalt. In the 1960s, Charles McDonald introduced the rubber modified asphalt called Overflex [24]. The technology of rubber modified asphalt in Poland was carried out, among others $[4,15,21]$. The first attempts to use rubber dust for modification of mineral-bituminous mixtures were most often experiments on a laboratory scale and concerned on the technology of rubber modified asphalt using the "dry" method [10].

SMA mixtures were originally developed in the 1960s in Germany in road constructions with high-traffic volume. These type of asphalt mixture has high content of asphalt binder and gap 
coarse aggregate gradation. From this reason it should be composed with stabilizing additives such as cellulose fibers or mineral fibers [17]. The rubber modifying of SMA mixtures can bring positive effects on the strength parameters of these mixtures and also on their stability during the transport and embedding process.

The first applications of the asphalt-rubber binder were in the US highway industry [12], mainly concerned the covering of damaged (cracked) concrete cement pavement.

The used rubber granulate can be introduced into the mineral-bituminous mix with two methods: dry process and wet process [22].

The dry process consists of adding mineral granulate with grain size up to $2.0 \mathrm{~mm}$ in an amount of about 2-3\%. As a result, we get a mineral-bituminous mixture with rubber grit inclusions. The addition of rubber reduces the stiffness of the mix thanks to which it increases its resistance to cracking. Despite the simplicity of the modification process itself, the dry process is not very popular because we get a mineral-bituminous mixture which is difficult to thicken (rubber granulate behaves elastically during thickening) which causes loosening of the mix structure. The result is a high content of free space in the mixture, significant absorbability, and low frost resistance.

The wet process is based on the earlier modification of the bitumen binder with a rubber granulate and the introduction of a finished asphalt-rubber binder into the mineral mix. The effect of the modification depends on the granulation of the rubber granulate, the amount of added rubber, the method of combining asphalt with rubber (temperature and mixing intensity), the time of mixing, the time of "maturing" of the new binder. Rubber granules are dosed in an amount of 10 to $20 \%$ in relation to the binder. Too much rubber granulate, especially on harder asphalts, results in a bituminous mineral mix with difficult workability during embedding.

Typical road asphalts are suitable for modification, however, it should be remembered that the addition of rubber granulate changes the properties of the binder. The type of binder used depends on the type of mineral-bituminous mix in which the asphalt-rubber binder will be used. The basic tests of the asphalt-rubber binder are viscosity, penetration at $25^{\circ} \mathrm{C}$, softening point according to R\&B (Ring and Ball method) and elastic recovery at $25^{\circ} \mathrm{C}$.

The use of rubber modification results in changes in the rheological properties of road asphalts $[7,18]$.

The grinding of rubber from used car tires is based on mechanical cutting and grinding, and the obtained product contains rubber, fabric, and metal. Grinding can be carried out by the cryogenic method or in normal atmospheric conditions [9].

\section{Materials and methods}

Scanning electron microscope (SEM) analysis showed that the crumped rubber (CR) has different surface depending on grinding method. An example of rubber after crushing in multiple magnifications - cryogenic method, is shown in Figure 1. Rubber granules having a regular graining (so-called crumb rubber [19], rubber dust or rubber powder), shredded at room temperature, are also often used to modify the asphalt - Figure 2. The subject of this work was the analysis of the modification of an asphalt binder with a rubber dust. 




1. Dimensions and shape of rubber grains shredded by the cryogenic method

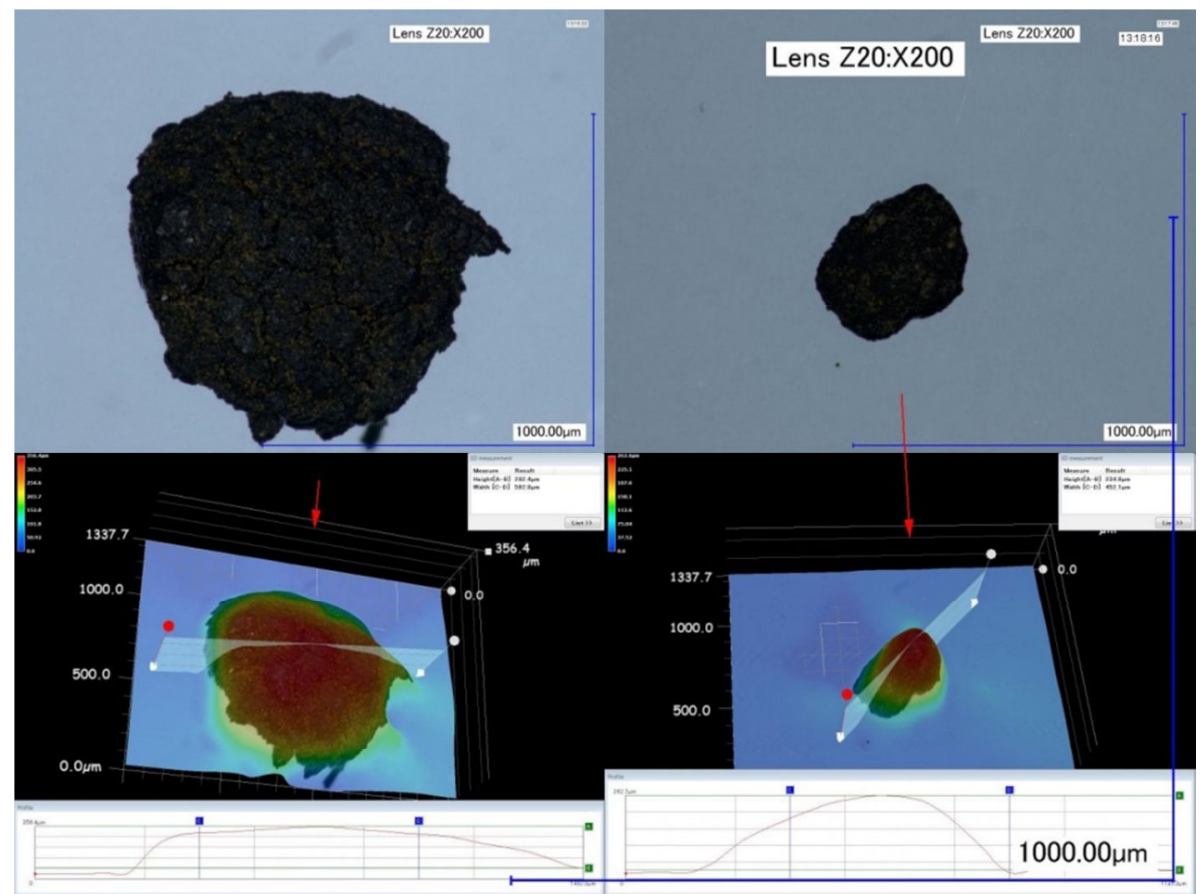

2. The view of rubber dust grains

The research program analyzed the impact of the use of rubber modification on the properties of bituminous binders and asphalt mixtures by the wet process. The tests took into account modified bitumen 45/80-55 and analogous with the addition of rubber marked 45/8055 AR. Studies show that the optimal addition of rubber at around $10 \%$ percent gives positive effects on the properties of future MMA mixtures [20].

All examinations were carried according to standard procedures which are used in European road laboratories (European standards EN). First stage of tests was to define basic properties of asphalts. Three general tests for asphalts were carried:

- softening temperature test according to EN 1427,

- penetration test according to EN 1426,

- dynamic viscosity test according to EN 13302.

These tests allowed to estimate, if modified asphalt may be used to make SMA mixtures.

Second stage of the experimental program, were tests of SMA mixtures. The mixtures were designed according to boundary grading curves - for aggregate, and design criterions, adequately to SMA demands [16]. The mixing process was carried on with guidelines presented in EN 12697-35. A compacting method was adapted to particular test samples, 
according to EN 13108-5 and EN 13108-20. After the compacting process, tests for SMA mixtures were carried. In the experimental program, following tests were used:

- durability on water and frost test according to EN 12697-12,

- rutting test according to EN 12697-22.

Results of all tests are presented further in this paper. The analysis of results can be helpful to enter the rubber modified mixtures to common road practice.

\section{Results and discussion}

\section{Asphalt binders}

At the beginning, the influence of the use of a rubber additive in an asphalt binder on penetration and the softening temperature was analyzed. These features are commonly used in the assessment of the suitability of bituminous binders for applications in selected layers of road surfaces. Penetration and softening temperature make it possible to assess the resistance of the future asphalt mixture to the formation of permanent deformation and low-temperature fractures. As a result of the test cycle, results for penetration were obtained - Table 1. The results of the softening point analysis of the bituminous binders used are listed in Table 2 .

Tab. 1. Penetration of the asphalts

\begin{tabular}{|c|c|c|}
\hline Asphalt type & \multicolumn{2}{|c|}{ Penetration at $25^{\circ} \mathrm{C}$} \\
\hline PMB 45/80-55 & {$[0,1 \mathrm{~mm}]$} & $45-80$ \\
\hline PMB 45/80-55 AR & {$[0,1 \mathrm{~mm}]$} & 49,0 \\
\hline
\end{tabular}

Tab. 2. The R\&B softening temperature

\begin{tabular}{|c|c|}
\hline Asphalt type & Softening temperature $\left[{ }^{\circ} \mathrm{C}\right]$ \\
\hline PMB 45/80-55 & $\geq 55$ \\
\hline PMB 45/80-55 AR & 55,8 \\
\hline
\end{tabular}

As a result of the experiment, it was found that the depth of penetration in the case of rubber modified asphalts is much lower than in the case of asphalt without a rubber additive. The results obtained are located in the lower part of the required range of penetration of modified asphalt. The $R \& B$ tests indicate that the rubber additive in the asphalt, which is sufficiently quantitative, does not cause major changes in the softening temperature compared to conventional modified binders. Obtained softening temperature results met the requirements for modified binders used for SMA layers according to [16].

In the dynamic viscosity tests, a Brookfield rotational viscometer was used. Four temperature levels were used to estimate the viscoelastic properties of the tested asphalts. The results of dynamic viscosity tests for rubber modified binder 45/80-55 AR are shown in Figures 3, 4, 5 and 6. 


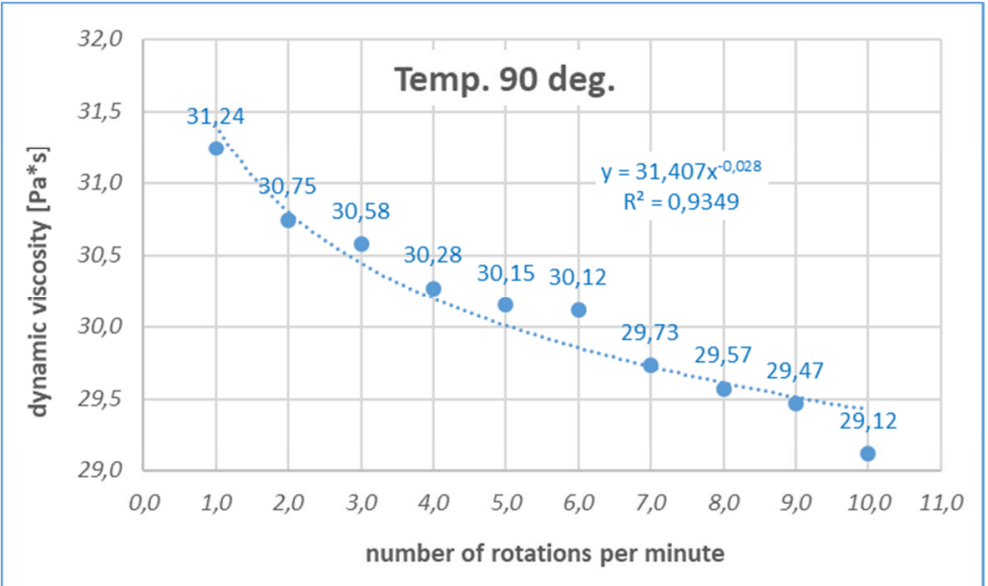

3. Asphalt dynamic viscosity at $90^{\circ} \mathrm{C}$

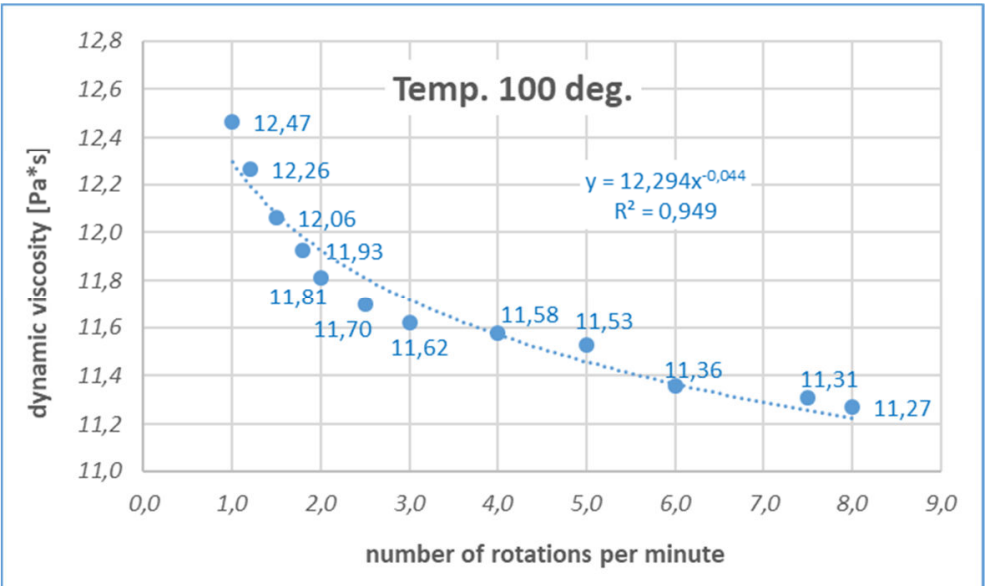

4. Asphalt dynamic viscosity at $100^{\circ} \mathrm{C}$

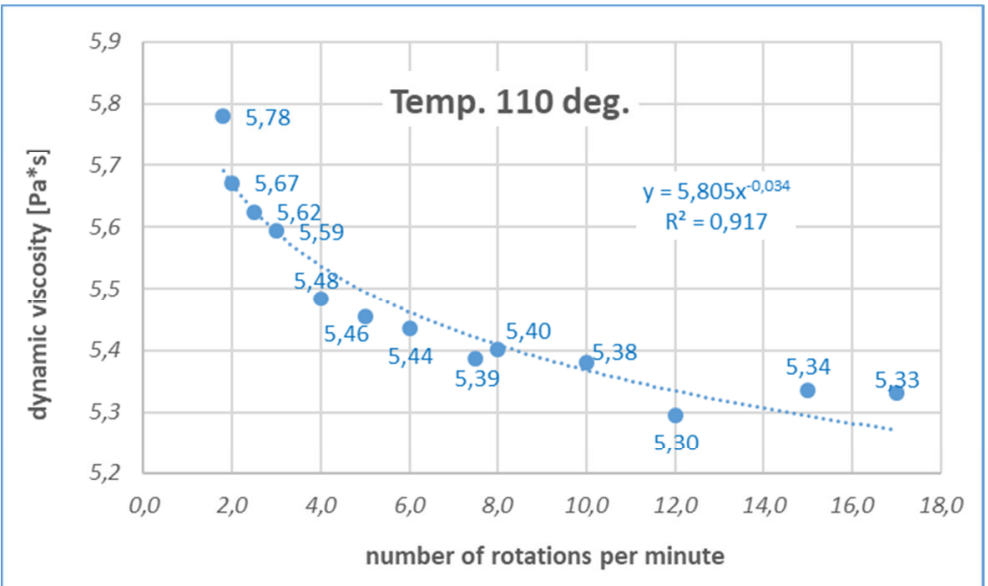

5. Asphalt dynamic viscosity at $110^{\circ} \mathrm{C}$ 


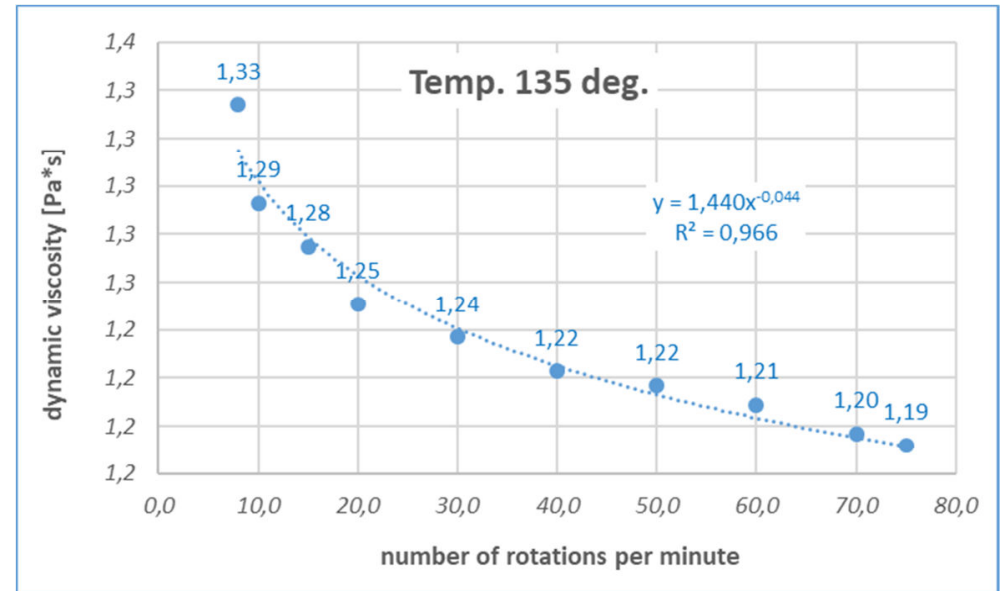

6. Asphalt dynamic viscosity at $135^{\circ} \mathrm{C}$

For polymer-modified asphalt, examples of viscosities are shown in Table 3 [3].

Tab. 3. Dynamic viscosity of conventional modified asphalt

\begin{tabular}{|l|c|c|c|}
\hline \multirow{4}{*}{$\begin{array}{c}\text { Dynamic } \\
\text { viscosity }\end{array}$} & Test temperature & Result & Unit \\
\cline { 2 - 4 } & $90^{\circ} \mathrm{C}$ & 44,33 & $\mathrm{~Pa}^{*} \mathrm{~s}$ \\
\cline { 2 - 4 } & $135^{\circ} \mathrm{C}$ & 1,12 & $\mathrm{~Pa}^{*} \mathrm{~s}$ \\
\cline { 2 - 4 } & $160^{\circ} \mathrm{C}$ & 0,22 & $\mathrm{~Pa}^{*} \mathrm{~s}$ \\
\hline
\end{tabular}

On the basis of the obtained research results, a relationship was developed showing the dynamic viscosity as a function of temperature for rubber modified asphalt, and this dependency was compared with the characteristic of a conventional asphalt binder 45/80-55 Figure 7.

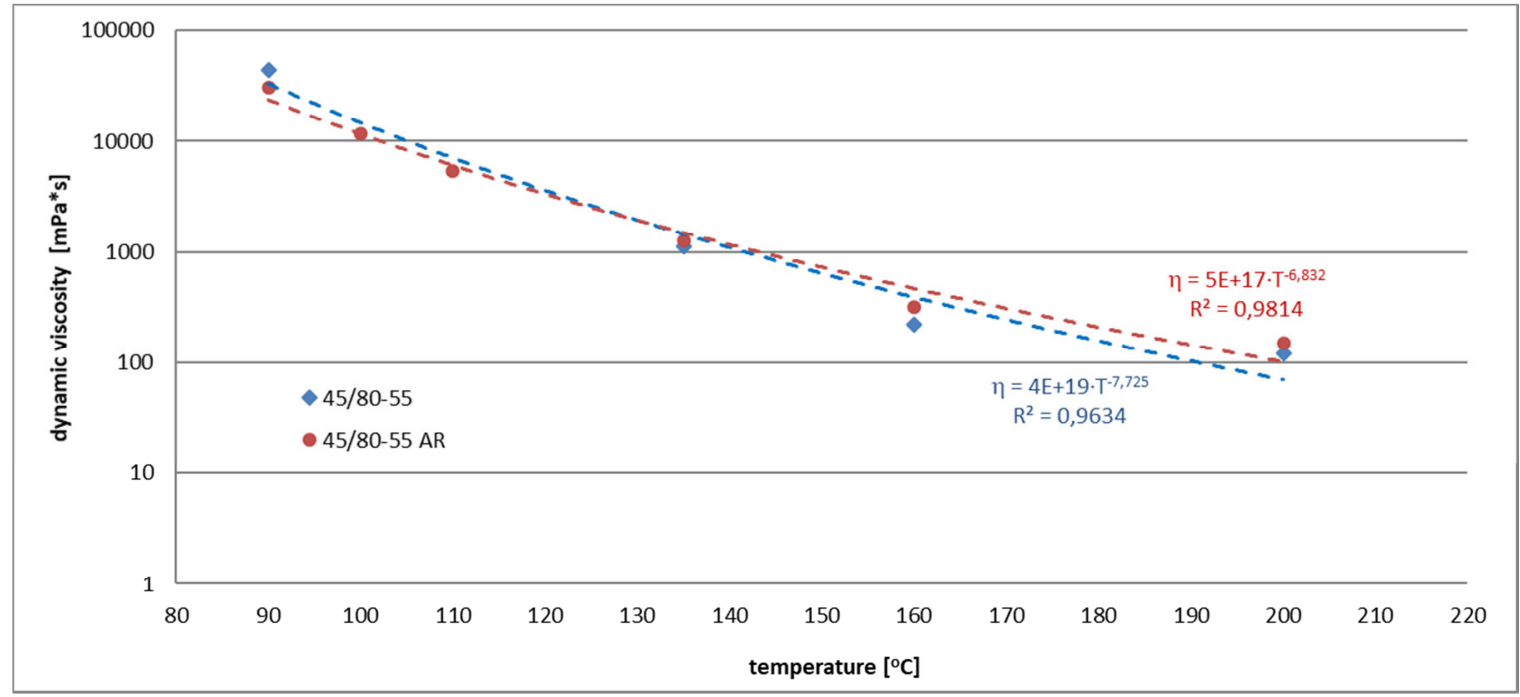

7. Asphalt dynamic viscosity as a function of temperature

It was found that at low temperatures, the traditional polymer modified asphalt has a higher viscosity, while at higher operating temperatures, the analogous asphalt with the addition of rubber shows higher viscosity. Interestingly, asphalts exhibit comparable viscosity at a temperature close to the incorporation of the SMA mixture into the road surface (approx. $135-140^{\circ} \mathrm{C}$ ). It can, therefore, be concluded that the use of a rubber additive in an asphalt 
binder will not worsen the compaction conditions of the asphalt mixture. Rubber modified asphalt can, therefore, be successfully used in the manufacture of SMA mixtures.

\section{SMA mixtures}

The aim of the laboratory tests was to compare the recipe of the SMA type mixture, with the addition of rubber dust, with a conventional mixture based on polymer modified asphalt. For comparative purposes, a study was carried out on the SMA mixture based on the frequently used modified asphalt 45/80-55, without the addition of rubber.

As the superstructure of the mineral-asphalt mixtures, the volcanic aggregate was used, in the amounts shown in table 4. The filler was limestone flour. The addition of fibers stabilizing the structure of SMA, preventing excessive flow of the asphalt binder, during transport and installation of the mixture was also used. Two types of binders were implemented: conventional asphalt and asphalt with $10 \%$ rubber dust (to the weight of the binder). Rubber addition was replacing also the stabilizing fibers.

Tab. 4. The composition of mineral-asphalt mixtures

\begin{tabular}{|c|c|c|}
\hline Component & $\begin{array}{c}\text { Share in } \\
\text { mineral mixture }\end{array}$ & $\begin{array}{c}\text { Share in mineral- } \\
\text { asphalt mixture }\end{array}$ \\
\hline$[-]$ & {$[\%]$} & {$[\%]$} \\
\hline Filler & 10,0 & 9,4 \\
\hline Fine broken aggregate $0 / 2$ & 13,0 & 12,2 \\
\hline Coarse aggregate $2 / 5$ & 11,0 & 10,3 \\
\hline Coarse aggregate 5/8 & 19,0 & 17,8 \\
\hline Coarse aggregate 8/11 & 47,0 & 44,1 \\
\hline Asphalt binder & & 6,2 \\
\hline Adhesive agent & & $0,3 \%$ of asphalt \\
\hline Stabilizing agent & & $0,45 \%$ of MM \\
\hline
\end{tabular}

In the mineral-asphalt mixtures, an optimal graining curve was applied, located in the field of good grain size according to [16] - Figure 8.

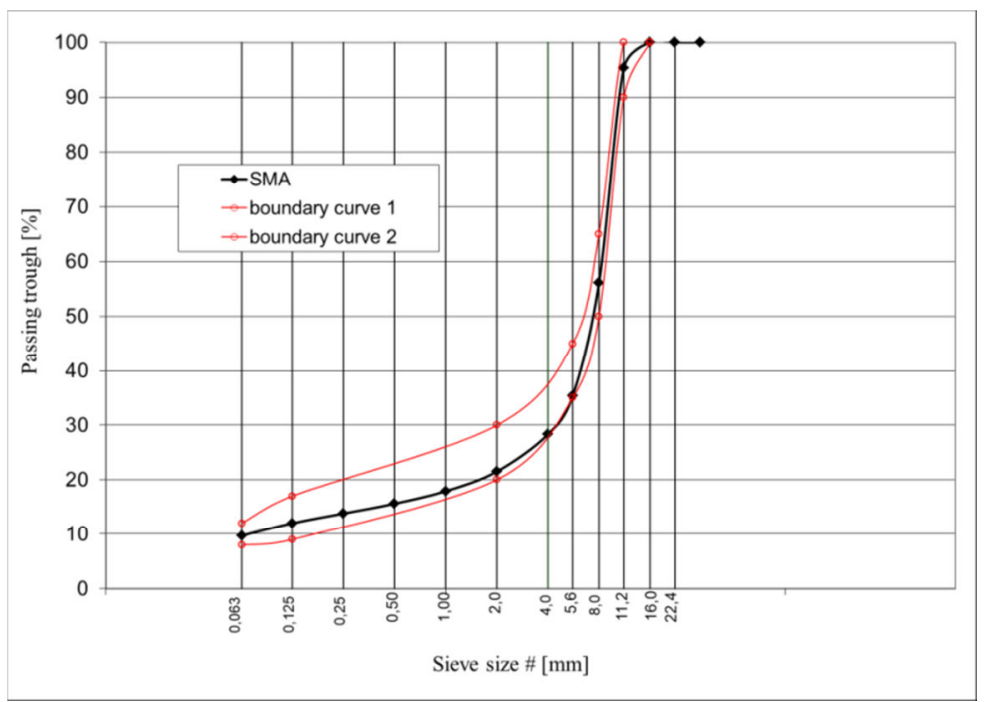

8. Grading curve of SMA mixtures 
In the asphalt mixtures research program, tests were used to assess the properties of SMA mixtures, while designing them and verifying correctness, used according to [16]. Basic research includes water resistance and resistance to permanent deformations - rutting.

The comparison of the properties of the tested mineral-asphalt mixtures is presented in Figures 9 to 11.

ITSR factor (water durability)

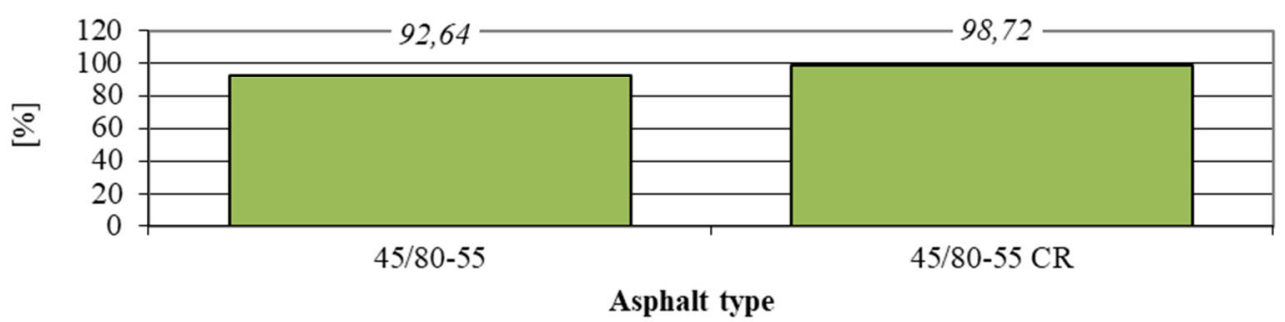

9. Change of MMA resistance to water

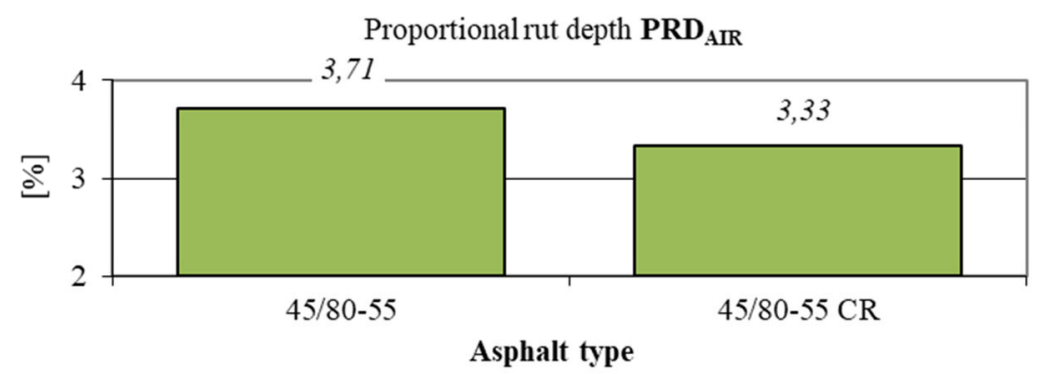

10. Rutting of SMA mixtures

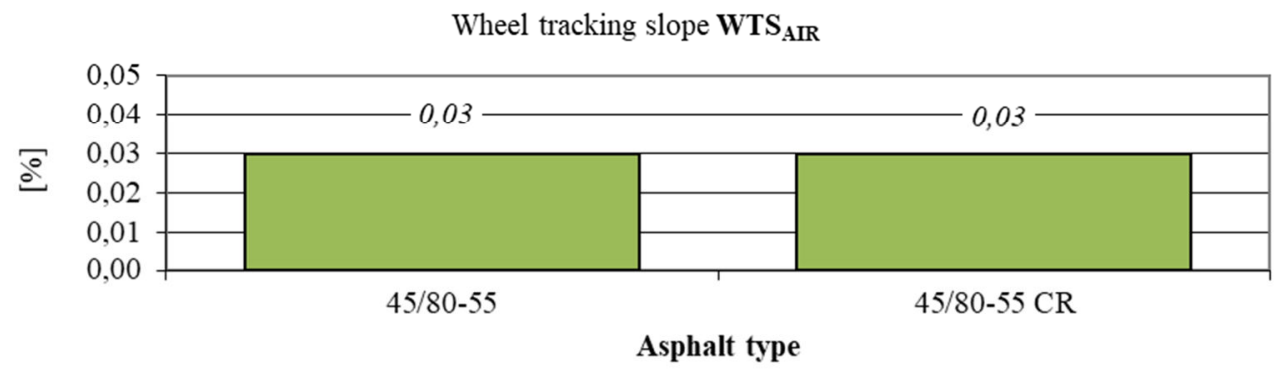

11. Rutting of SMA mixtures cont.

During the laboratory tests, a significant improvement in the properties of mineralasphalt mixtures was demonstrated after the use of a rubber modified binder. After applying this type of binder, a significant improvement in the resistance of MMA to water and frost was achieved. In the sensitivity test of water samples, an additional freezing cycle was applied. The resistance to rutting was also greater in the case of mixtures based on asphalt with the addition of rubber. The rutting speed was analogous for both types of mineral-asphalt mixtures. The addition of rubber will favorably affect the tested characteristics. The results of the analyses were compared with the technical requirements set for ordinary SMA mixtures table 5 . 
Tab. 5. Criteria for designing SMA mixtures [16]

\begin{tabular}{|c|c|c|c|c|c|}
\hline $\begin{array}{c}\text { Properties } \\
{[-]}\end{array}$ & Symbol & Unit & \multicolumn{2}{|c|}{ Result } & Requirement \\
\hline \multirow{2}{*}{$\begin{array}{c}\text { Resistance to rutting (small apparatus, } \\
60^{\circ} \mathrm{C}, 10000 \text { cycles). The maximum } \\
\text { proportional rut depth }\end{array}$} & \multirow[b]{2}{*}{$\mathrm{PRD}_{\mathrm{AIR}}$} & \multirow[b]{2}{*}[\%]{} & $45 / 80-55$ & 3,71 & \multirow[b]{2}{*}{$\leq 5,0$} \\
\hline & & & $\begin{array}{c}45 / 80-55 \\
\text { AR }\end{array}$ & 3,33 & \\
\hline \multirow{2}{*}{$\begin{array}{c}\text { Resistance to rutting (small apparatus, } \\
60{ }^{\circ} \mathrm{C}, 10000 \text { cycles). Wheel tracking } \\
\text { slope (rutting speed). }\end{array}$} & \multirow[b]{2}{*}{ WTS $_{\text {AIR }}$} & \multirow{2}{*}{$\begin{array}{c}{\left[\mathrm{mm} / 10^{3}\right.} \\
\text { cykli }]\end{array}$} & $45 / 80-55$ & 0,03 & \multirow[b]{2}{*}{$\leq 0,30$} \\
\hline & & & $\begin{array}{c}\text { 45/80-55 } \\
\text { AR }\end{array}$ & 0,03 & \\
\hline \multirow{2}{*}{$\begin{array}{l}\text { Indirect tensile strength index }\left(25^{\circ} \mathrm{C} \text {, }\right. \\
1 \text { freezing cycle, samples compacted } \\
2 * 35 \text { blows })\end{array}$} & \multirow[b]{2}{*}{ ITSR } & \multirow[b]{2}{*}{ [\%] } & $45 / 80-55$ & 92,64 & \multirow[b]{2}{*}{$\geq 90$} \\
\hline & & & $\begin{array}{c}45 / 80-55 \\
\text { AR }\end{array}$ & 98,72 & \\
\hline
\end{tabular}

MMA with the addition of rubber dust should be evaluated positively. The technical requirements for the tests have been met.

\section{Conclusions}

The results of asphalt binder tests show an improvement in the properties of the asphalt used after rubber modification. It was found that the stiffness in the lower temperature range, represented by the penetration parameter, in the case of rubber modified asphalts is higher than in the case of asphalts without a rubber additive. On the other hand, susceptibility in the upper temperature range, described by the softening temperature, for asphalts with a rubber additive is analogous in comparison to conventional modified binders. At low temperatures, the traditional polymer modified asphalt has a higher viscosity, while at higher operating temperatures, the analogous asphalt with the addition of rubber shows higher viscosity. It is interesting to note that asphalts exhibit a comparable viscosity at a temperature close to the installation of the SMA mixture in the road surface (approx. $135-140^{\circ} \mathrm{C}$ ).

As a result of the analysis, it was found that MMA containing rubber modified asphalt 45/80-55 AR meets the requirements of technical guidelines [16], and can be approved for use on road surfaces.

Tests of road material have been carried out and the analyzes allow to draw the following conclusions:

- The use of a rubber additive changes the properties of asphalt binders.

- There is a certain amount of rubber additive - about $10 \%$, which allows optimal modification of asphalt binders.

- The use of the wet process gives positive results when it comes to the strength parameters of mineral-asphalt mixtures.

- The rubber modifying of SMA mixtures bring positive effects on stability (by reducing asphalt viscosity) during the transport and embedding.

- mineral mixtures with the addition of rubber dust, meet the design criteria for SMA layers and can be used in road construction.

- The reuse of waste materials can significantly reduce the consumption of natural resources.

- The use of rubber waste can reduce the negative impact on the environment and the emission of harmful greenhouse gases.

\section{Conflict of interest}


The author declare no conflict of interest.

\section{Funding}

This research did not receive any specific grant from funding agencies in the public, commercial, or not-for-profit sectors.

\section{Source materials}

[1] Abu El-Maaty Behiry A. E., Utilization of cement treated recycled concrete aggregates as base or subbase layer in Egypt, Ain Shams Engineering Journal (2013) 4, 661-673, https://doi.org/10.1016/j.asej.2013.02.005.

[2] Amoussou1 R.I.H.D.T., Sasaki M., Shigeishi M., An Application of Pulsed Power Technology and Subcritical Water to the Recycling of Asphalt Concrete, Procedia Engineering 143 (2016), 1-9, https://doi.org/10.1016/j.proeng.2016.06.001.

[3] Błażejowski K., Olszacki J., Peciakowski H., Asphalt guide, ORLEN Asfalt sp. z o.o., 2014.

[4] Gaweł I., Kalabinska M., Pilat J., Road Asphalts, WKiŁ, Warsaw, 2001.

[5] Gong J., Liu Y., Wang Q., Cai Z. Xi, J., Ding G., Xie H., Performance evaluation of warm mix asphalt additive modified epoxy asphalt rubbers, Construction and Building Materials 204 (2019), 288-295, https://doi.org/10.1016/j.conbuildmat.2019.01.197.

[6] Gupta T., Siddiqueb S., Sharmaa R. K., Chaudharyc S., Behaviour of waste rubber powder and hybrid rubber concrete in aggressive environment, Construction and $\begin{array}{llll}\text { Building } & \text { Materials 283-291, }\end{array}$ https://doi.org/10.1016/j.conbuildmat.2019.05.080.

[7] Hailong J., Guangtao G., Yong Z., Yinxi Z., Kang S., Yongzhong F., Improved properties of polystyrene-modified asphalt through dynamic vulcanization., Polymer Testing 21 (2002), 633-640, https://doi.org/10.1016/S0142-9418(01)00135-0.

[8] Jina R., Chenb Q., Investigation of concrete recycling in the U.S. construction industry, $\begin{array}{llllll}\text { Procedia } & \text { Engineering } & 118 & \text { (2015), } & 894 & -\end{array}$ https://doi.org/10.1016/j.proeng.2015.08.528.

[9] Khalilia M., Jadidia K., Karakouziana M., Amirkhanianb S., Rheological properties of modified crumb rubber asphalt binder and selecting the best modified binder using AHP method, Case Studies in Construction Materials 11 (2019), e00276, https://doi.org/10.1016/j.cscm.2019.e00276.

[10] Koba H., The influence of the rubber additive on asphalt mixtures properties, III International Conference: Durable and Safe Road Pavements, Kielce, 1997.

[11] Krishnamoorthya R. R., Davida T. K., Bin Mastorb E..N. A., Nadarasac Ir. K., Repair of Deteriorating Pavement Using Recycle Concrete Materials, Procedia Engineering 142 (2016), 371 - 382, https://doi.org/10.1016/j.proeng.2016.02.064.

[12] Lo Presti D., Recycled Tyre Rubber Modified Bitumens for road asphalt mixtures: A literature review, Construction and Building Materials 49 (2013), 863-881, https://doi.org/10.1016/j.conbuildmat.2013.09.007.

[13] Nováková I., Mikulica K., Properties of concrete with partial replacement of natural aggregate by recycled concrete aggregates from precast production, Procedia Engineering 151 (2016), 360 - 367, https://doi.org/10.1016/j.proeng.2016.07.387.

[14] Ossa A., García J.L., Botero E., Use of recycled construction and demolition waste (CDW) aggregates: A sustainable alternative for the pavement construction industry, $\begin{array}{lllll}\text { Journal of Cleaner Production } & 135 \quad \text { (2016), 379-386, }\end{array}$ https://doi.org/10.1016/j.jclepro.2016.06.088.

[15] Radziszewski P., Kalabińska M., Piłat J., Using the rubber dust from old vehicle tires to asphalt modifications, Elastomery 4(5), (2001). 
[16] Road and Bridge Research Institute, Asphalt pavements on national roads, WT-2 2014, Asphalt mixtures, Technical requirements, Warsaw, 2014.

[17] Sadeghian M., Namin M. L., Goli H., Evaluation of the fatigue failure and recovery of SMA mixtures with cellulose fiber and with SBS modifier, Construction and Building Materials 226 (2019), 818-826, https://doi.org/10.1016/j.conbuildmat.2019.07.308.

[18] Sienkiewicz M., Borzędowska-Labuda K., Zalewski S., Janik H., The effect of tyre rubber grinding method on the rubber-asphalt binder properties, Construction and Building Materials 154 (2017), 144-154, https://doi.org/10.1016/j.conbuildmat.2017.07.170.

[19] Singh B. B., Mohanty F., Das S.S., Swain S.K., Graphene sandwiched crumb rubber dispersed hot mix asphalt, Journal of Traffic and Transportation Engineering (English Edition), Volume 7, Issue 5 (2020), 652-667, https://doi.org/10.1016/j.jtte.2019.02.003.

[20] Skotnicki Ł. Z., Koba H., Szydło A., The SMA mixtures with rubber asphalt, Drogownictwo, 65(11) (2010) 374-378.

[21] Sybilski D., Application of the rubber wastes in road engineering, Przegląd Budowlany 5 (2009), 37-44.

[22] Tahami S. A., Mirhosseini A. F., Dessouky S., Mork H., Kavussi A., The use of high content of fine crumb rubber in asphalt mixes using dry process, Construction and Building Materials 222 (2019), 643-653, https://doi.org/10.1016/j.conbuildmat.2019.06.180.

[23] Wagih A.M., El-Karmoty H.Z., Ebid M., Okba S. H., Recycled construction and demolition concrete waste as aggregate for structural concrete, HBRC Journal (2013) 9, 193-200, https://doi.org/10.1016/j.hbrcj.2013.08.007.

[24] Weidong C., Study on properties of recycled tire rubber modified asphalt mixtures using dry process, Construction and Building Materials 21 (2007), 1011-1015, https://doi.org/10.1016/j.conbuildmat.2006.02.004. 